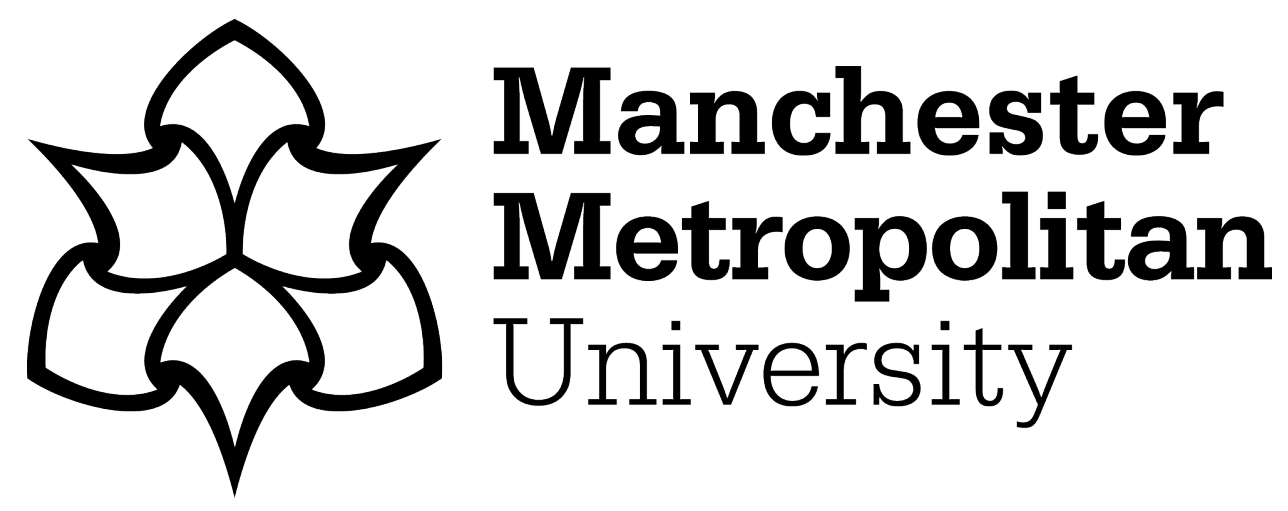

Hansen, M, Fyall, $A$ and Spyriadis, T ORCID logoORCID: https://orcid.org/0000-0003-0451-6058 (2020) Adventure or amusement? Image and identity challenges for the aerial adventure industry and implications for positioning and policy. Anatolia, 31 (3). pp. 423-435. ISSN 1303-2917

Downloaded from: https://e-space.mmu.ac.uk/626289/

Version: Accepted Version

Publisher: Taylor \& Francis

DOI: https://doi.org/10.1080/13032917.2020.1741408

Please cite the published version 


\title{
Adventure or amusement? Image and identity challenges for the aerial adventure industry and implications for positioning and policy
}

\author{
Marcus Hansen $\left(\mathbb{D}^{\mathrm{a}}\right.$, Alan Fyall $\mathbb{D}^{\mathrm{b}}$ and Thanasis Spyriadis $\mathbb{D}^{\mathrm{c}}$ \\ ${ }^{a}$ North Wales Business School, Wrexham Glyndwr University, Wrexham, UK; ${ }^{b}$ Rosen College of Hospitality \\ Management, University of Central Florida, Orlando, FL, USA; 'Department of Marketing, Retail and Tourism, \\ Faculty of Business \& Law, Manchester Metropolitan University, Manchester, UK
}

\begin{abstract}
This paper seeks to address the changing image and identity of the aerial adventure industry as it becomes increasingly commercialized, which has led to uncertainty over its positioning within either adventure tourism or amusement rides. Such a positioning is critical in order to mitigate the problems caused by an inappropriate identification and image that contributes to poor inspections, poor procedures and policies, and ultimately, poor perceived risks and safety. In an industry where one serious injury impacts all operators, it is essential for all stakeholders to have collective "buy in" to effective policies that are standardized across the entire industry. The current identity confusion has merely led to misconceptions from public stakeholders. Through a qualitative case-study, this paper finds that aerial adventure parks share characteristics with adventure tourism and amusement rides and so resembles a hybrid. This is largely due to the presence of inherent risk and the role of the participant, both of which are less present on amusement rides. The paper therefore calls for state agencies to identify the activity as a stand-alone activity and for the subsequent regulations and policies to reflect this hybrid status.
\end{abstract}

\author{
ARTICLE HISTORY \\ Received 5 September 2019 \\ Accepted 9 March 2020 \\ KEYWORDS \\ Adventure tourism; aerial \\ adventure; risk \\ management; co-creation \\ experience; amusement \\ rides; attraction \\ management
}

\section{Introduction}

Since turning commercial in 2008, the US aerial adventure industry [AAI] has become one of the fastest growing sectors in the United States, with over 250 adventure parks in operation today and a current annual growth rate in excess of 13\% (API, 2019; Billock et al., 2015; Smith, 2015; Sweeney, 2016; Wagstaff, 2015). Despite this, limited research exists on this tourism sub-sector and on adventure tourism in the US in general. Aerial adventure parks [AAP] can be described as obstacle courses or rope courses set between 10 and $60 \mathrm{ft}$ in the air, consisting of rope bridges, tight ropes, cargo nets, ziplines and more (Treego, 2014). Harnesses and some form of belay system are worn and used to keep participants attached to belay cables, whilst traversing through courses (Hansen, Fyall et al., 2019). Whilst participants are provided initial training on how to use such equipment, they are largely responsible for their own safety once on the course (Bromley Mountain Ski Resort, 2019 Hansen, Hjalager et al., 2019). Typically, courses are set in the trees or on poles with platforms for participants to stand on and some type of obstacle or zipline connecting the trees/poles. The participant's objective is to make their way through the course, often relying on their own problem-solving, strength and stamina.

Much like adventure tourism is becoming increasingly commercialized, so is the aerial adventure industry (Giddy, 2018; Hansen, Fyall et al., 2019). Originally seen as an educational tool with its 
roots in Outward Bound USA in the 1960s (Wagstaff, 2015), the activity's biggest component today is the commercial side with a focus on pay-for-play (Smith, 2015). However, despite the activity seemingly cementing its position as a niche sector within the tourism industry in recent years, academia and industry stakeholders appear to struggle in identifying the activity appropriately. Seemingly, it is currently suffering from an identity crisis. Indeed, academic research into the AAI is very limited to date (Billock et al., 2015; Hansen, Fyall et al., 2019) with this study one of the first to focus solely on this new activity.

At present, concerns within the industry exist over whether the AAI should be identified as adventure tourism, as the name would seem to imply, or amusement rides. On the face of it, such issues may seem minor or in fact trivial. Yet, the appropriate identification of the aerial adventure industry has considerable managerial and policy implications on the private stakeholders as well as the expectations of the public stakeholder in charge of regulating the activity, as this paper will highlight. Previous research has already recognized the importance of appropriate regulations as adventure tourism becomes increasingly commercialized (Giddy, 2018). Specifically to the aerial adventure industry, an inappropriate identification may lead to poor inspections, poor procedures and policies at state level, which could have dire consequences from a risk management point-ofview in regards to public safety. The impact of such is felt by both public and private stakeholders, through the design, construction, operation and inspection of the courses. Thus, it should be in all stakeholder's interest to have effective policies in place, knowing an incident at one park will have a negative impact on the industry as whole (author, reference not provided to protect anonymity).

Interestingly, the activity has recently been identified as an adventure tourism activity (author, reference not provided to protect anonymity). Nevertheless, as the activity becomes ever-more commercial, it inevitably loses certain elements of adventure, perhaps developing a warped image of being an activity similar to amusement rides. In fact, the image and identity of the industry is changing somewhat from a traditional educational focus to a contemporary pay-to-play focus, though it retains many of its original features (Hansen, Hjalager et al., 2019). Bearing this in mind, the paper seeks to identify AAPs appropriately and address the managerial and policy implications this would have on the industry as a whole, knowing that effective regulation improves public safety levels and may also lead to an improved competitive advantage for the industry (Pulido-Fernández et al., 2019).

One differentiator between amusement rides and adventure tourism is the role of the participant. The rollercoasters traditionally associated with amusement parks rely on state-of-the-art technology where the participant's experience is planned and organized down to the smallest details (Milman, 2010). Similarly to adventure tourism, the aim is to excite and elicit thrill of the participants, but in an excessive manner, allowing the participants to enjoy the ride with little-tono influence on the activity, making for a more passive experience (Holyfield, 1999). On the other hand, adventure tourism provides exceedingly interactive activities, in which the role of the participant is more predominant (Clinch \& Filimonau, 2017). Yet, commercialization and changes to the role of the participant may have critical consequences with regards to risk management (Giddy, 2018; Hansen, Fyall et al., 2019). Giddy (2018) for example, reported on a relative lack of experience, often none, among participants in commercial adventure tourism, in relation to the specific activity at hand, which is also likely to shape the participants' image of the activity.

Understanding this role, in relation to risk management procedures, therefore becomes critical to our understanding of the subsequent managerial and policy implications when positioning the industry appropriately (Giddy, 2018; Wang et al., 2019). Unlike previous research, which has mainly been interested in the consumer and, or, staff experience, this paper instead goes beyond this and seeks to understand how the industry is perceived by state agencies and the managerial and policy implications this may have going forward. As such, this paper seeks to address the changing identity and image of the aerial adventure industry and how it differs from amusement rides in the hope this might facilitate more efficient and accurate regulation. At the time of writing, it is estimated thirteen states regulate aerial adventure parks (Hubbard-Merrell, 2019), meaning many have yet to explore policies within this sphere. 


\section{Literature review}

As of yet it would seem that there is no set agreement on the definition of adventure tourism (C. Cater, 2013; McKay, 2013; Swarbrooke, 2003; UNWTO, 2014). Mykletun (2018, p. 319) described it as a somewhat "blurred concept and a multifaceted field" recognizing the various and, at times, vastly different types of activities residing under this label. Indeed, Rantala et al. (2018) argued that adventure tourism is perhaps more of a category as opposed to a concept. The Adventure Travel Trade Association (ATTA, 2013) defines adventure tourism as a trip that includes two of three elements: physical activity, natural environment and cultural immersion and includes both domestic and international tourists. Swarbrooke's (2003, p. 32) influential work on adventure tourism found that two different levels existed; 'soft' and 'hard' adventure. Soft implying that some adventure is included, but high levels of safety exists [e.g. bird watching or canopy tours] (Villalobos-Céspedes et al., 2010). Hard adventure represents physically demanding activities and higher levels of risk [e.g. caving and trekking] (McKay, 2013).

However, more recently, some have attempted to distance adventure tourism from the "soft" and "hard" dichotomy, arguing that the commercial side of the industry is positioned somewhere in between the two with aspects of both "soft" and "hard" (C. Cater, 2013; Varley \& Semple, 2015). Hansen et al. (2019) recently identified AAPs as adventure tourism attractions, yet industry has yet to follow suit. In light of the numerous new activities continuously being added to the commercial adventure tourism umbrella (Mykletun, 2018), the fact that the AAI has yet to be classed is perhaps understandable. Indeed, neither the UNWTO (2014) nor the ATTA (2013) have yet to list it as an adventure tourism activity. Nevertheless, aerial adventure activities include physical activity and are, for the most part, present in the natural environment, thus meeting ATTA's criteria.

The participant experience has been described as 'a voluntary engagement in novel, uncertain and most often emotionally intense activity' (Holyfield, 2005, p. 174). Today, adventure is defined by its psychological characteristics, including seeking excitement, challenge, fear and selfdevelopment (Cheng et al., 2018). This is achieved by having participants actively interact with the provider (Grissemann \& Stokburger-Sauer, 2012). In turn, an experience is co-created and not simply consumed by the participant. Indeed, this is one of the many motivating factors behind engaging in adventure tourism - the promise of a highly self-defined experience (Prebensen \& Xie, 2017; Sfandla \& Björk, 2013). Whether traditional or commercial adventure tourism, co-creation is critical to the overall success of the adventure experience (Mathisen, 2019).

"Adventure" implies action, meaning this is not a passive experience, but one which is engaging, absorbing and requires commitment, both mentally and physically, from the participant as they go through the activity and through interaction with staff (Rantala et al., 2018). Indeed, the roles of staff and participants in relation to risk management of commercial adventure tourism has already been highlighted in previous research (Clinch \& Filimonau, 2017; Giddy, 2018; Wang et al., 2019). To the contrary, amusement rides are inherently more passive experiences (Holyfield, 1999). Yet, much like amusement rides, participants in commercial adventure tourism do not necessarily have past experience in relation to the activity at hand (Giddy, 2018), which might be attributable to the identity crisis of the aerial adventure industry.

\section{Adventure tourism: risk as a motivation}

Similar to AAPs, adventure tourism comes from a background of outdoor sports and recreation (Chen et al., 2017; Hall, 1992; Wagstaff, 2015). Much adventure tourism research has focussed on the motivations of participants and to date it is widely agreed upon that risk is essential to adventure, although much of this is perceived risk (Clinch \& Filimonau, 2017; Rantala et al., 2018; UNWTO, 2014). Giddy and Webb (2016) described adventure tourism as activities involving risks, thus arguably supporting this argument. In addition, whilst risk traditionally has negative connotations, in aerial adventure and adventure tourism, the connotation is largely positive (Wang et al., 2019). It is worth 
noting, though, this is a managed risk that, to a certain extent, becomes a perceived risk instead in commercial adventure tourism (Mackenzie \& Kerr, 2013). However, this comes with a caveat: participants desire the feeling of taking risks, but do not seek actual harm and most likely lack the required skills to deal with such (Buckley, 2012; Fletcher, 2010; Giddy, 2018; Hansen et al., 2019). This paradoxical relationship with risk becomes apparent with actual risk being negative, whilst the perceived risk enables participants to experience positive emotions (Mykletun, 2018). Both are present, yet the extent to which actual risk surfaces is often reliant on the actions behind the people involved in the activity, be they participants or the provider.

As with AAPs, adventure tourism has undergone considerable changes, most notably the commercialization and mass accessibility of its activities (Giddy \& Webb, 2016; Rantala et al., 2018; Rickly \& Vidon, 2017). Here, the emphasis is on providing high throughput, low difficulty experiences for the unskilled, meaning activities that were once for the elites in their field are now readily accessible to most people, including families and children (Buckley, 2007; Mykletun, 2018; Rantala et al., 2018). Holyfield (2005, p. 174) point out that 'today's adventure companies now compete to provide excitement and other intense emotions while guaranteeing the safety of those who do not actually wish to risk their lives experiencing these sensations'. Research suggests that whilst responsibility of participant safety has shifted from participants to operators as adventure tourism has commercialized, some responsibility still lies with the participant through their behaviours (C. I. Cater, 2006; Wang et al., 2019). Seemingly, risk is sufficiently more inherent in this type of activity as compared to traditional amusement rides, although this is still somewhat manufactured. Nevertheless, by combining AAPs together with amusement rides, do state agencies run the risk of not fully understanding the differences and thereby implementing policies reflecting this? As an example, Tennessee has grouped these two activities together, defining amusement rides as such (State of Tennessee, 2019, p. 2):

Amusement device means: any mechanical or structural device that carries [...] a person, or that permits a person to walk along, around or over a fixed or restricted route or course [...] for the purpose of giving persons' amusement, pleasure, thrills or excitement.

Amusement rides and adventure tourism clearly have these characteristics in common and these are undoubtedly adding to the warped image and resulting identity crisis of the aerial adventure industry. Yet, the literature indicates the excitement and thrills are derived from actual risk within adventure tourism, with the role of the participant, and its impact on risk management, providing a key differentiator of the two (Rantala et al., 2018). Arguably, when actual risk is present to this extent, this should also have considerable managerial and policy implications. The impact of such is felt by both public and private stakeholders, through the design and construction of the parks, operating and inspecting the parks to the public participating in the experience. Thus, it should be in all stakeholder's interest to have effective policies in place. By considering AAPs an amusement ride, are state agencies sufficiently equipped to differentiate between such inherently different activities? Contrary to the state of Tennessee, the state of Colorado (2019) (Tennessee, 2019) recognizes the two as being different, defining AAPs and amusement rides separately in their Amusement Rides and Devices Regulations. By failing to identify the industry accurately, is the public stakeholder putting consumer safety at risk? Bearing this in mind, the purpose of this paper is to understand whether AAPs should be identified as an amusement ride or as an adventure tourism activity. The following sections seek to determine this identification.

\section{Methodology}

A single case study approach of the US AAI was chosen to offer a deeper understanding of the industry and how it is perceived by public and private stakeholders. Yin (2014) argues a single case study is most appropriate when studying a single group of people. " Twenty semi-structured interviews were undertaken and took place over Skype with the conversations recorded and afterwards transcribed by the authors. To provide some structure to the interviews, an interview guide 
consisting of a number of questions relevant to this paper, was devised by the authors. These questions were largely derived from the the literature. Non-probability sampling techniques were utilized as using random sampling was not deemed feasible. This was due to only certain stakeholders being considered for this paper, and not all cases within the sample universe, with the consumer omitted from the data gathering. This decision was made in light of their lack of specific knowledge of the subject. It was deemed that the public stakeholder [the government] represent the consumer as the legislator. A combination of convenience sampling, snowball sampling and purposeful sampling techniques were employed. Data gathering continued until saturation was reached, as originally opined by Glaser and Strauss (1967). First step in the sampling strategy was defining the sampling universe (Robinson, 2014).

Smith (2015) identified 252 AAPs in the US, though little specific information was available on these parks. There are 50 states in the US, all of which may or may not regulate the industry. However, the exact amount of builders and insurance providers within the US is not clear. The Association for Challenge Course Technology [ACCT's] Preferred Vendor Member list has 34 US-based Preferred Vendor Members (PVM), constituting builders who are ACCT members and meet certain criteria. As a result, the PVM list acted as a guidance for this paper's sampling strategy. Further, only insurance providers offering insurance for organizations within the AAI were approached. With these facts in mind, the researcher had at least 336 stakeholders, and thus potential participants as industry stakeholders, namely private, public and third sector stakeholders from the US AAI were approached to participate. The type of interview participant included state agents, builders, operators, insurance agents and standard-writers from the AAI. Senior managers from the respective organizations were approached to participate due to their knowledge and influence in regards to the AAI. However, participants were not asked to compare the AAI and amusement rides. The participants were from various states, including Florida, New Hampshire, North Carolina and Colorado. The sampling strategy was further aided by Mitchell et al. (1997) theory of stakeholder identification and salience. This framework recognizes all stakeholders, but prioritizes certain stakeholders over others. As a result, it was deemed this framework was most suitable for this paper. Stakeholder legitimacy was the attribute used to guide stakeholder identification for the paper.

As the case study focussed on an industry, but gathered data through speaking to various stakeholders from the public and private sector, an embedded analysis was employed. This allowed the case study to focus on the industry as a whole, whilst not forgetting the "sub-units", or stakeholders, that ultimately make up the industry (Yin, 2014).

Once the data was transcribed it was analysed using thematic analysis, with the development of themes guided by the literature review. This also meant an abductive approach was utilized to develop thematic codes. Thematic analysis increases the accuracy and sensitivity of the researcher's understanding and interpretation of the data collected (Boyatzis, 1998). The themes developed for the paper were supported by segments from the interviews (Creswell, 2007). The thematic analysis process involved three stages: deciding on sampling and design issues, developing themes and a code and finally validating and using the code (Boyatzis, 1998). Given the interview guides were guided by the literature, it was inevitable that themes in the data collected would also reflect the literature. As an example, theme one centred on the activity's relationship with risk, a critical subject in adventure tourism. Two codes were devised, namely adventure and amusement in lieu of the purpose behind the paper. Three themes were subsequently developed: providing a thrilling, but safe experience, aerial adventure park: an amusement ride, and The People V. Aerial Adventure Parks.

\section{Results}

\section{Theme one: providing a thrilling, but safe experience}

The data portrayed an industry having a paradoxical relationship with risk. Participants desire a thrilling and immersive experience. Yet, the participants do not want to experience actual 
harm. As such, the industry seeks to create thrilling experiences, whilst keeping the consumer returning by avoiding the confrontation of actual danger. Thus, perceived risk has become key to the attraction of AAPs, similarly to adventure tourism, though some interview participants acknowledged the inherent risks present too, which it would seem was also the critical difference between AAPs and amusement rides. As participant 8, an engineer within the industry, pointed out:

I think it's [perceived risk] actually very important. Without a perceived risk it's not adventurous [...]nobody wants to be experiencing real danger [...] but any time you climb something you are at risk of falling $[\ldots]$.

Further, not only is perceived risk key to the attraction of the activity, evidently, maintaining this balance between perceived and actual risk is therefore also critical to the management of it. When asked about this paradoxical relationship with risk participant 6 , the CEO of a national builder, pointed out:

... that's probably where its magic is, and as providers of those products and services, can we create a very risky experience for people that is not really risky, it's actually pretty safe?

This latter point was further stressed by participant 5, a site manager and course designer of a national builder, acknowledging that perceived risk is essentially actual risk that has been managed and thereby delivering the desired experience to the consumer:

[...] there's a perceived risk that brings out the desire for that little bit of thrill-seeking that everybody has. [...] the entire program is crafted in such a way to mitigate as much risk as possible.

Through perceived risk, participants are able to experience an immersive activity. The data seemed to indicate that people are, in part, attracted to AAPs due to the predictability of everyday life today. This type of, somewhat, manufactured adventure enables the participants to encounter a much deeper experience, as opposed to the traditional amusement ride. For example, participant 6 pointed out that:

People like to feel alive and that experience of having your life somewhat on the edge [...] you're doing something very tangible and physical and you're very conscious and aware [...] there's an adrenaline rush with it.

Similarly, it was argued that consumers today desire more engaging and challenges activities during recreational time, which push their boundaries in ways that their every-day lives do not. Participant 9, an operations manager of an operator, argued that:

most people have to seek adventure and challenges through recreation [...] their day-to-day life does not provide that anymore.

From the data it appeared that the perceived risk is key to the activity. However, clearly there's a fine line between perception and actual risk and the latter does indeed exist. Seemingly, depending on the effectiveness of risk management policies and procedures in place, there will always be some levels of inherent risk involved, but compared to other adventure sports, such as rock climbing, it is much more hidden. Nevertheless, understanding this aspect of the activity would seem critical to state agencies when implementing policies, knowing the level of risk within the activity is supposedly more apparent as compared to amusement rides. If state policies do not reflect this, they may be rendered ineffective as a result, which could have dire consequences with regards to public safety.

\section{Theme two: aerial adventure park: an amusement ride?}

One prevalent theme within the data contended that perception from the public agency-side created challenges to effective risk management. The data indicated the few states that do regulate the industry tend to identify it as an amusement ride or carnival ride, which is, perhaps, not a identificationification the industry concurs with. The data pointed to a number of differentiators between the two types of activities, mainly relating to the levels of co-creation and experience in general, be it the level of involvement of the participant or the level of risk. These factors, once again, enable the participant to 
encounter an experience which is, seemingly, considerably more immersive than that of a typical amusement ride. A more immersive experience adds another level of risk, which is not present in amusement rides. Arguably, the state agencies may therefore fail to appreciate this difference, not understanding the considerably different role of the participant on an AAP as compared to an amusement ride. This argument was, for example, put forth by participant 8 :

The amusement park is not supposed to have [...] an actual risk, it's only supposed to be perceived, but with an aerial adventure course, because the participation is higher, that risk is very different.

Indeed, it would seem amusement rides simply do not allow for such levels of participant involvement, and thus does not provide levels of engagement to the extent that AAPs do. It was, for example, argued personal growth is, perhaps, not as evident, if at all, in traditional amusement ride activities, such as rollercoasters. Some interview participants argued that the two activities are, as a result, vastly different, one offering a considerably more immersive experience than the other for participants. For example, participant 11 commented that:

[...] [...] it's [amusement rides] basically just a ride. An aerial adventure park is: you're interacting, you're sweating, you're moving, you're actively moving between elements [...] in a carnival ride you're sitting there. Like, you're not supposed to move!.

Participant 12 was facing government regulation in their particular state and was concerned whether AAPs would fall under amusement rides. They argued, the implications of such policies could increase the challenges of risk management, with AAPs offering an activity where participants, to a certain extent, are responsible for their wn safety. The participant commented:

I'm hoping that we won't be lumped in with that [amusement rides], because this really isn't an amusement ride, it's more of an independent sport [...]an amusement ride is, basically, you're strapped in and you can't detach and you go on a ride.

Indeed, participant involvement seems to be the differentiator between AAPs and amusement rides. This is seemingly, a critical point for state agencies to understand when implementing policies for the industry Participant 17 highlighted this difference:

Aerial adventure parks are a bit more challenging and a bit more involved. [...] because there's the amount of independent play and exploration.

Further, participant 5 described the difference between AAPs and amusement rides, also pointing out the interaction between staff and participants taking place. Once again, the possible implications of misunderstanding the nature of this activity, became obvious:

[...] most of those [amusement parks and carnival rides], you teach the guy who, that you hit the green button to turn it on and you hit the red button to turn it off, [...] to transfer that over to something that has such a guide or monitor driven [...] They're responsible for a lot, including some higher-end rescues.

The data indicated that some state agencies perceive AAPs in a similar light to amusement rides, which, in turn, brings challenges to risk management. Indeed, with perception playing a key role, if accidents are getting fewer but worse, this could potentially create a perception issue. According to the data, the main differentiator between the two is the level of participation required from participants at AAPs. Indeed, participants and staff are, to a certain extent, responsible for their own safety. Once again, understanding such considerable differences would seem imperative for public agencies. Seemingly, misclassifying the industry will lead to ineffective policies and procedures, which threaten the long-term sustainability of the industry as a result.

\section{Theme three: the people V. Aerial Adventure Parks}

A recurring theme within the data was the critical role of the human factor within this activity at various levels, particularly in regards to risk management. Some participants commented that the 
vast majority of failures were due to human error, as opposed to mechanical faults. Perhaps not surprisingly, participant 15 described human error as the main area of concern in risk management, arguing that "that's definitely the one that jumps out at you the most". Participant 9 commented on the challenges that participants bring to effective risk management, arguing that such challenges make the activity inherently different from traditional amusement rides. Participant 9 stated:

[...] they [the participants] have far more control of the experience on an aerial adventure than they do on a roller coaster. So, I would say the most difficult aspect that we deal with, [...] is the participants themselves $[\ldots]$ there's a component of the safety that relies on the participants themselves that they may, or may not, fully understand.

Whilst the human factor seemingly differentiates AAPs from amusement rides, it is also an apparent cause for concern within the industry. Many participants spoke of the increased levels of risk involved, when handing responsibility over to the participants, even if it is just at a minor level. Participant 12 spoke of the challenges of dealing with the human factor in risk management:

[...] the human factor, it can more than quintuple the danger. Any time you have humans involved in a program or in a system, there's always a risk that something could go wrong.

Regardless of the amount of training participants go through, it seemed that participants were still capable of complicating matters. Participant 18, for example, commented on the challenges of getting participants to follow directions, which in turn has led to incidents:

$[\ldots]$ the most serious of accidents have been is [...] not following directions [...] I think the biggest threat that they have is making sure that they monitor the patrons to make sure that they're following instructions.

As such, it is perhaps not surprising that the industry feels it is imperative the various state governments identifyify the industry appropriately. Participant 3 argued that getting the classification of the activity correct could indeed be critical to participant safety:

If you tell people that it's an amusement ride and it's safe, the type of people that are going to be drawn to it are people that $[\ldots]$ are going to be much, much less willing to accept the fact there is risk in what they're doing.

Thus, participant involvement appears to be key to AAPs, though it also clearly presents the industry with challenges to risk management, an aspect that would seemingly need to be reflected upon within state policies. Participant 11 indeed defined it as such: "the biggest risk are the guests breaking the rules and having an accident".

Nevertheless, according to participant 4 these differences are slowly being eradicated due to the demand for safer experiences, a development that appears to be creating challenges to achieving effective risk management. As a result, the participant argued the industry was moving towards becoming more like an amusement ride, perhaps even on purpose, albeit slowly:

[...] participant involvement is one of the biggest things that we're currently dealing with, [...] it's hard to manage that risk, because you can't control people it's turning more into a passive experience, more like a rollercoaster-situation.

Indeed, whilst the human factor seemingly still plays a critical role, it would appear that due to technology and innovation, this factor is becoming less apparent and, to a certain extent, managed out of the system. Participant 15 commented:

I think it still plays a significant role [the role of the participant], but I think it is a changing role. participant perception that plays a huge role on the risk management-side of things [...] I think it's the operator's, [...] to [...] manage their perception.

As such, the data suggested that the level of participation taking place among participants also provides a great challenge to effective risk management. The interview participants seemingly 
alluded to risk always being present as long as the activity consisted of high-levels of co-creation, due to human error and participants choosing not to follow the rules. Whilst the industry is seemingly shifting towards less participant involvement, it would appear this has yet to fully take place. Thus, understanding this part of the activity would still seem to be critical to state agencies and should thus have implications on their policies.

\section{Conclusion and implications}

This paper set out to identify the AAI accurately as either an adventure tourism activity or an amusement ride. This was deemed necessary in light of the managerial and policy implications such identification might have on public safety, through poor state inspections and poor policies and procedures being put in place, which may all be detrimental to the risk management processes within the industry. An incident at one park does not simply negatively impact that individual operator, but the industry as whole, thereby making the industry unsustainable in the long-term. The data would seem to suggest the industry suffers from an identity crisis with state agencies also appearing unclear of how to identify the AAI, which in turn has led to a misunderstanding of the activity in some cases, with it predominantly being identified as an amusement ride. Figure 1, below, has been developed through the information gathered in the data highlighting the characteristics of the aerial adventure industry and highlights similar characteristics to adventure tourism as well as amusement rides. Similarly to amusement rides, for example, the emphasis is on providing mass appeal and low difficulty experiences for the unskilled, meaning these activities are now readily accessible to most people, including families and children (Buckley, 2007; Mykletun, 2018; Rantala et al., 2018).

However, according to the data and the literature, contrary to amusement rides, some responsibility still resides with the participants in the AAI, in light of the level of participation required (Clinch \& Filimonau, 2017; Mathisen, 2019). Responsibility would seem to be shared in this case

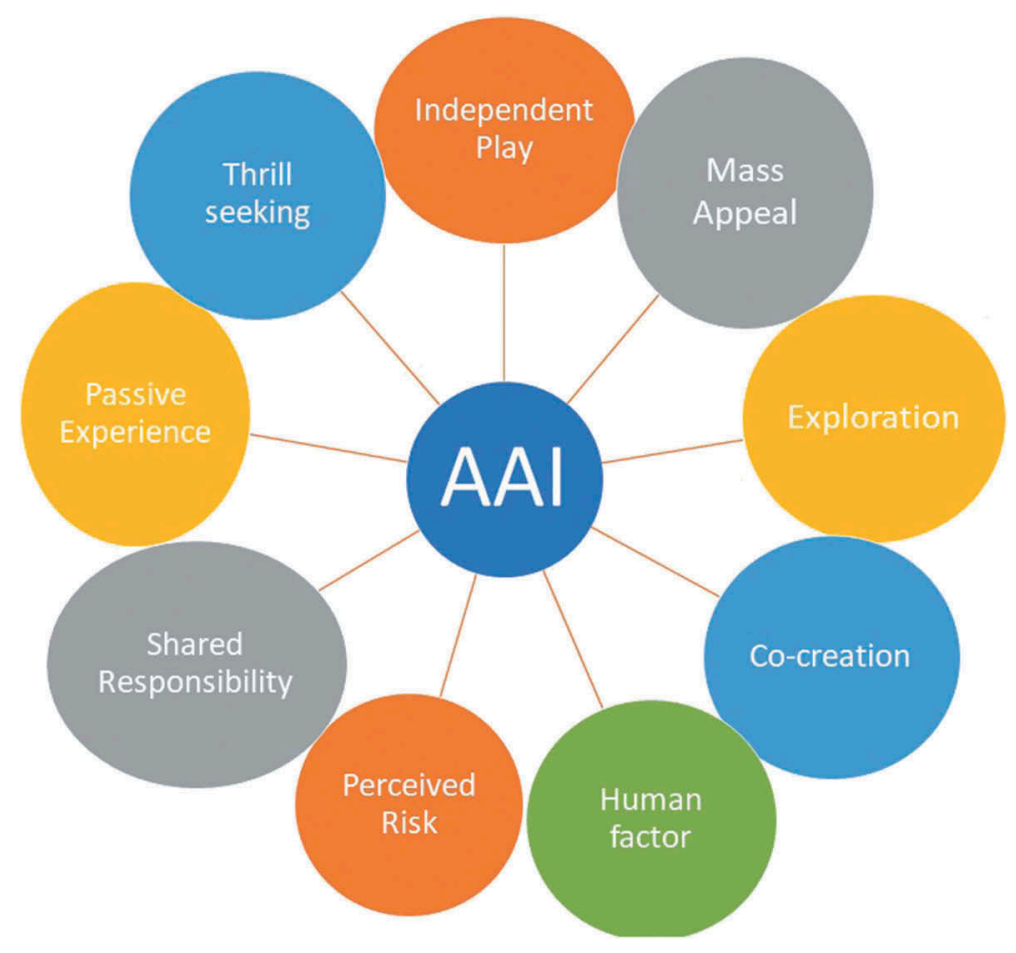

Figure 1. Characteristics of the AAl. 
between the operator and the participant, when responsibility is placed largely on the operator of amusement rides. Evidently, as the industry commercializes, its image changes as well and as a result it increasingly shares similar characteristics with amusement rides, including thrillseeking, low-skilled participants and a passive experience element. Yet, the resulting identity crisis brings challenges to risk management due to the levels of participation of both staff and participants being vastly different at AAPs as compared to amusement rides, which in turn results in inaccurate expectations of public agencies who may not understand nor appreciate the impact this has on the activity. The result, conceivably, has negative consequences for all stakeholders within the industry. It is likely that the AAI is moving more towards "soft" commercial adventure tourism, towards a more passive experience, and away from "hard" adventure, a move which is largely facilitated through innovation (Giddy, 2018; Hansen et al., 2019). However, this transition also ties in with Varley and Semple (2015) argument that commercial adventure tourism sits in-between "soft" and "hard" adventure tourism. One could argue commercial adventure tourism, and aerial adventure parks, is a hybrid version of adventure tourism and amusement rides.

The human factor would appear to play a much greater role in risk management than compared to amusement rides. Recent research has recognized the impact on risk management the behaviour of staff and participants has within adventure tourism (Clinch \& Filimonau, 2017; Mathisen, 2019; Wang et al., 2019). Whilst aerial adventure parks thrive on the element of perceived risks, similarly to commercial adventure tourism (Hansen et al., 2019; Rantala et al., 2018), actual risks still remain if not managed appropriately, with particular emphasis on the human factor. The paradoxical relationship with risk is clearly present within the AAI as well (Mykletun, 2018). Interview participants, for example, spoke of amusement ride attendants simply having to push buttons to start and stop rides with participants having little to no involvement in the process of the ride itself. However, on AAPs, much of the risk derives from the level of participation of staff and participants as a result of certain levels of independent play and exploration existing and whilst these levels are decreasing due to innovation, they still present the industry with challenges. Despite moving towards soft commercial adventure, some levels of shared responsibility still remain. Co-creation still plays a critical role in the overall experience of the activity, a typical feature of adventure tourism (Mathisen, 2019).

Focussing on the mechanical side of the attraction is clearly not sufficient, when public agencies should also be investigating areas such as staff and participant training in an effort to minimize the likelihood of human error occurring. Bearing this in mind, identifying the activity appropriately is seemingly critical for the effective regulation of it. By identifying the industry inappropriately would suggest the public agencies do not aptly understand the activity and thereby run the risk of implementing ineffective policies, which could hamper risk management procedures, lead to issues over public safety and possibly opening the state(s) up to liability in case of incidences. As such, the current identity crisis could render the industry unsustainable in the long-term. Considering the inherent levels of risk identified within this paper, it is perhaps somewhat alarming that only thirteen states currently regulate this activity.

Whilst this paper finds considerable similarities between AAPs and amusement rides, as highlighted in Figure 1, notably through the motivations of participation such as thrill seeking and their mass appeal, it also contends that in light of the inherent risk clearly present, identifying it as an amusement ride would simply ignore the risk potential of the activity. Certainly, the data portrayed an industry which feels the activity is quite incomparable to amusement rides. Evidently, through its identity crisis, the public state agencies fail to take into account the considerable differences, which, as highlighted within this paper, may have serious consequences for all the stakeholders within the industry going forward, particularly in regards to public safety and the overall sustainability of the industry going forward. Thus, implementing the appropriate policies is vital. Indeed, this could add a competitive advantage to the industry. Alternatively, this paper has argued, an incident at one park does not simply affect the individual organization, but has negative consequences on the industry as a whole, meaning it is in all stakeholder's best interests to have an appropriate identification and effective safety policies and procedures in place. 
Through the literature and extensive data gathering, the authors argue that this activity should be classed as a hybrid version of adventure tourism activities and amusement rides, a common development of commercial adventure tourism activities, as a result of the decreasing role of the participant and acknowledge the likelihood of it one day being considered an amusement ride. As such, it should be classed as a stand-alone activity, much like the state of Colorado has done. With only thirteen states currently regulating the industry and an increasing awareness of the industry in light of recent serious incidents, it is likely more states will follow with their own policies. The findings of this paper should therefore be applicable going forward as states seek to implement policies on the aerial adventure industry.

\section{Disclosure Statement}

No potential conflict of interest was reported by the authors.

\section{Notes on contributors}

Dr. Marcus Hansen is a lecturer of hospitality, tourism \& events at Wrexham Glyndwr University in Wales. He has a growing bibliography of publications in adventure tourism, of which his $\mathrm{PhD}$ was also the focus. Before entering academia, Dr. Hansen spent a number of years as a business owner in the adventure tourism industry in the US.

Dr. Alan Fyall is the Associate Dean of Academic Affairs, the Visit Orlando Endowed Chair, the Interim Chair of the Tourism, Events and Attractions Department and Graduate Programs' Director at the Rosen College of Hospitality Management, University of Central Florida, and is a member of UCF's National Center for Integrated Coastal Research. He has published widely in the areas of tourism and destination marketing and management including 22 books. Dr. Fyall has conducted numerous consulting and applied research projects for clients across the globe. Dr. Fyall was an external supervisor of Dr. Hansen's PhD.

Dr. Thanasis Spyriadis is a senior lecturer of tourism management at Manchester Metropolitan University in England. Dr. Spyriadis is an expert in destination management, the area of focus of his $\mathrm{PhD}$ and leads the MSc International Tourism Management programme at Manchester Metropolitan University. Dr. Spyriadis supervised the $\mathrm{PhD}$ of Dr. Hansen.

\section{ORCID}

Marcus Hansen (D) http://orcid.org/0000-0002-5053-9667

Alan Fyall (D) http://orcid.org/0000-0003-0058-2410

Thanasis Spyriadis (D) http://orcid.org/0000-0003-0451-6058

\section{References}

Adventure Travel Trade Association [ATTA]. (2013). Adventure tourism market study. Adventure Travel Trade Association and the George Washington University, 1-15. [Accessed 28/08/2018]. Available at: http://files.adven turetravel.biz/docs/research/adventure-tourism-market-study-2013-web.pdf

Billock, R. M., Anderegg, J. J., Mehan, T. J., Chounthirath, T., \& Smith, G. A. (2015). Zipline-related injuries treated in US EDs, 1997-2012. The American Journal of Emergency Medicine, 33(12), 1745-1749. https://doi.org/10.1016/j. ajem.2015.08.022

Boyatzis, R. E. (1998). Transforming qualitative information: Thematic analysis and code development. Sage.

Bromley Mountain Ski Resort. (2019). Aerial adventure park [online]. Retrieved October 25, 2019, from https://www. bromley.com/the-mountain/attractions/aerial-adventure-park/

Buckley, R. (2007). Adventure tourism research: A guide to the literature. Tourism Recreation Research, 31(2), 75-83. https://doi.org/10.1080/02508281.2006.11081265

Buckley, R. (2012). Rush as a key motivation in skilled adventure tourism: Resolving the risk recreation paradox. Tourism Management, 33(4), 961-970. https://doi.org/10.1016/j.tourman.2011.10.002

Cater, C. (2013). The Meaning of Adventure. In S. Taylor, P. Varley, \& T. Johnston (Eds.), Adventure tourism: Meaning, experience \& learning (pp. 7-18). Routledge.

Cater, C. I. (2006). Playing with risk? Participant perceptions of risk and management implications in adventure tourism. Tourism Management, 27(2), 317-325. https://doi.org/10.1016/j.tourman.2004.10.005 
Chen, C.-M., Lin, Y.-L., \& Chang, T.-T. (2017). The effects of macroeconomic and weather conditions on the business cycle of Taiwan's adventure tourism. Current Issues in Tourism, 20(5), 447-454. https://doi.org/10.1080/13683500. 2016.1187584

Cheng, M, Edwards, D, Darcy, S, \& Redfern, K. (2018). A tri-method approach to a review of adventure tourism literature: bibliometric analysis, content analysis, and a quantitative systematic literature review. Journal Of Hospitality \& Tourism Research, 42(6), 997-1020.

Clinch, H., \& Filimonau, V. (2017). Instructors' perspectives on risk management within adventure tourism. Tourism Planning \& Development, 14(2), 220-239. https://doi.org/10.1080/21568316.2016.1204360

Creswell, J. W. (2007). Qualitative enquiry and research design: Choosing among five approaches. Sage.

Fletcher, R. (2010). The Emperor's new adventure: Public secrecy and the paradox of adventure tourism. Journal of Contemporary Ethnography, 39(1), 6-33. https://doi.org/10.1177/0891241609342179

Giddy, J., \& Webb, N. (2016). The influence of the environment on motivations to participate in adventure tourism: The case of the Tsitsikamma. South African Geographical Journal, 98(2), 351-366. https://doi.org/10.1080/ 03736245.2015.1028990

Glaser, B., \& Strauss, A. (1967). The discovery of grounded theory. 1967. Weidenfield \& Nicolson, London, 1-19.

Giddy, J. K. (2018). A profile of commercial adventure tourism participants in South Africa. Anatolia, 29(1), 40-51. https://doi.org/10.1080/13032917.2017.1366346

Grissemann, U. S., \& Stokburger-Sauer, N. E. (2012). Customer co-creation of travel services: The role of company support and customer satisfaction with the co-creation performance. Tourism Management, 33(6), 1483-1492. https://doi.org/10.1016/j.tourman.2012.02.002

Hall, C. M. (1992). Adventure, sport and health tourism. Adventure, Sport and Health Tourism, 141-158, Belhaven Press: London. ISBN: 1852930721.

Hansen, M., Fyall, A., Spyriadis, T., Rogers, D. and Brander-Brown, J. (2019). Collaborative industry risk management in adventure tourism: A case study of the US aerial adventure industry. Journal of Outdoor Recreation and Tourism. In Press..

Hansen, M., Fyall, A., Spyriadis, T., Rogers, D., \& Brander-Brown, J. (2019). Motivating stakeholder collaboration within the aerial adventure industry. International Journal of Tourism Research, 21(3), 311-322. https://doi.org/10. $1002 /$ jtr.v21.3

Hansen, M., Hjalager, A. M., \& Fyall, A. (2019). Adventure tourism innovation: Benefitting or hampering operations? Journal of Outdoor Recreation and Tourism, 28, 100253. https://doi.org/10.1016/j.jort.2019.100253. 21(3), $311-322$.

Holyfield, L. (1999). Manufacturing adventure: The buying and selling of emotions. Journal of Contemporary Ethnography, 28(1), 3-32. https://doi.org/10.1177/089124199129023352

Holyfield, L. (2005). Adventure without risk is like disney. Routledge.

Hubbard-Merrell. (2019). United States aerial adventure course regulations. [online]. Hubbard Merrell Engineering. https://www.hubbardmerrell.com/aerial-adventure-course-engineering/aerial-adventure-course-regulations/\#ten nessee-regs

Insider, Adventure Park (2019). State of the industry report 2018. [online]. [Accessed 29/02/20]. Available at: https:// www.arivalevent.com/adventure-park-insider-state-of-the-industry-report/.

Mackenzie, S. H., \& Kerr, J. H. (2013). Stress and emotions at work: An adventure tourism guide's experiences. Tourism Management, 36, 3-14. https://doi.org/10.1016/j.tourman.2012.10.018

Mathisen, L. (2019). Storytelling: A way for winter adventure guides to manage emotional labour. Scandinavian Journal of Hospitality and Tourism, 19(1), 66-81. https://doi.org/10.1080/15022250.2017.1411827

McKay, T. (2013). Adventure Tourism: Opportunities and management challenges for SADC destinations. Acta Academia, 45(3), 30-62. ISSN : 0587-2405

Milman, A. (2010). The global theme park industry. Worldwide Hospitality and Tourism Themes, 2(3), $220-237$. https://doi.org/10.1108/17554211011052177

Mitchell, R. K., Agle, B. R., \& Wood, D. J. (1997). Toward a theory of stakeholder identification and salience: Defining the principle of who and what really counts. Academy of Management Review, 22(4), 853-886. https://doi.org/10. 5465/amr.1997.9711022105

Mykletun, R. J. (2018). Adventure tourism in the North - Six illustrative cases. Scandinavian Journal of Hospitality and Tourism, 18(4), 319-329. https://doi.org/10.1080/15022250.2018.1524999

Prebensen, N. K., \& Xie, J. (2017). Efficacy of co-creation and mastering on perceived value and satisfaction in tourists' consumption. Tourism Management, 60, 166-176. https://doi.org/10.1016/j.tourman.2016.12.001

Pulido-Fernández, J. I., Cárdenas-García, P. J., \& Espinosa-Pulido, J. A. (2019). Does environmental sustainability contribute to tourism growth? An analysis at the country level. Journal of Cleaner Production, 213, 309-319. https://doi.org/10.1016/j.jclepro.2018.12.151

Rantala, O., Rokenes, A., \& Valkonen, J. (2018). Is adventure tourism a coherent concept? A review of research approaches on adventure tourism. Annals of Leisure Research, 21(5), 539-552. https://doi.org/10.1080/11745398. 2016.1250647

Rickly, J. M., \& Vidon, E. S. (2017). Contesting authentic practice and ethical authority in adventure tourism. Journal of Sustainable Tourism, 25(10), 1418-1433. https://doi.org/10.1080/09669582.2017.1284856 
Robinson, O. C. (2014). Sampling in interview-based qualitative research: A theoretical and practical guide. Qualitative Research in Psychology, 11(1), 25-41. https://doi.org/10.1080/14780887.2013.801543

Sfandla, C., \& Björk, P. (2013). Tourism experience network: Co-creation of experiences in interactive processes. International Journal of Tourism Research, 15(5), 495-506. https://doi.org/10.1002/jtr.v15.5

Smith, M. R. (2015). Aerial adventure park - trends, statistics and leading practices. Adventure Park Insider. http:// www.slideshare.net/MichaelSmith351/2015-aerial-adventure-park-trends-statistics-and-leading-practices $-52820699$

State of Colorado, (2019). Revised amusement rides regulations effective 7/ 30/15[online]. https:/www.colorado.gov/ pacific/ops/RevisedAmusementRegulations073015

Swarbrooke, J., Beard, C., Leckie, S., \& Pomfret, G. (2003). Adventure tourism: The new frontier. Routledge: London.

Sweeney, T. (2016). On belay systems. Adventure Park Insider. Retrieved from https://adventureparkinsider.com/onbelay-systems/

State of Tennessee, (2019). Definition of amusement device [online]. https://www.tn.gov/workforce/employers/safety -health/regulations-compliance/regulations_compliance-redirect/amusement-devices/redirect-amusementdevice-unit/definition.html

Treego. (2014). What is treego. http://www.treego.ca/

UNWTO. (2014). Global report on adventure tourism.

Varley, P., \& Semple, T. (2015). Nordic slow adventure: Explorations in time and nature. Scandinavian Journal of Hospitality and Tourism, 15(1-2), 73-90. https://doi.org/10.1080/15022250.2015.1028142

Villalobos-Céspedes, D., Galdeano-Gómez, E., \& Tolón-Becerra, A. (2010). Demand indicators for adventure tourism packages in Costa Rica: An exploratory analysis. Tourism and Hospitality Research, 10(3), $234-245$. https://doi.org/10.1057/thr.2010.7

Wagstaff, M. (2015). Challenge course programming - on the rise or in compromise? In B. Humberstone, H. Prince, \& K. A. Henderson (Eds.), Routledge international handbook of outdoor studies (pp. 217-226). Routledge.

Wang, J., Liu-Lastres, B., Ritchie, B. W., \& Pan, D.-Z. (2019). Risk reduction and adventure tourism safety: An extension of the risk perception attitude framework (RPAF). Tourism Management, 74, 247-257. https://doi.org/ 10.1016/j.tourman.2019.03.012

Yin, R. K. (2014). Case study research: Design and methods. Applied social research series (5th ed.). Sage. 